University of Nebraska - Lincoln

DigitalCommons@University of Nebraska - Lincoln

7-2011

\title{
Cedar Infestation Impacts Avian Communities along the Niobrara River Valley, Nebraska
}

January S. Frost

University of Nebraska-Lincoln

Larkin A. Powell

University of Nebraska-Lincoln, Ipowell3@unl.edu

Follow this and additional works at: https://digitalcommons.unl.edu/natrespapers

Part of the Natural Resources and Conservation Commons

Frost, January S. and Powell, Larkin A., "Cedar Infestation Impacts Avian Communities along the Niobrara River Valley, Nebraska" (2011). Papers in Natural Resources. 331.

https://digitalcommons.unl.edu/natrespapers/331

This Article is brought to you for free and open access by the Natural Resources, School of at DigitalCommons@University of Nebraska - Lincoln. It has been accepted for inclusion in Papers in Natural Resources by an authorized administrator of DigitalCommons@University of Nebraska - Lincoln. 


\title{
Cedar Infestation Impacts Avian Communities along the Niobrara River Valley, Nebraska
}

\author{
January S. Frost and Larkin A. Powell \\ School of Natural Resources, University of Nebraska-Lincoln, \\ 419 Hardin Hall, 3310 Holdrege Avenue, Lincoln, NE 68583-0974, U.S.A. \\ Corresponding author - L. A. Powell, 1powell3@unl.edu
}

\begin{abstract}
Habitat modification has the potential to cause changes in structure and composition of bird communities. Our goal was to determine the response of Songbird community composition to eastern red cedar (Juniperus virginiana) removal in The Nature Conservancy's Niobrara Valley Preserve, Nebraska. We used point counts to survey birds in the riparian matrix of grassland and forest habitats. More than 60 species were recorded on surveys during $2004-2005$. We also use the program PRESENCE to determine the response of five species to various habitat components, including cedar density: House Wren (Troglodytes aedon), Spotted Towhee (Pipilo maculates), Ovenbird (Seiurus aurocapillus), Red-eyed Vireo (Vireo olivaceus), and Indigo Bunting (Passerina cyanea). Species richness estimates were highest in open and mixed habitat patches. Local populations of Ovenbirds and Red-eyed Vireos responded positively to cedar density, whereas House Wren numbers declined as cedar density increased. Cedar abundance explained the most variation in bird community similarity between survey points; species richness increased as cedar density decreased. Habitat structure and composition drove variation in community composition and population abundance at fine, local scales within the Preserve. Fine-scale management to remove cedar from local areas should increase diversity of avian species by maintaining a matrix of habitat types. Cedar removal at any scale will affect the composition of bird communities, and we encourage a structured approach to management decisions.
\end{abstract}

Keywords: avian community, eastern red cedar, forest management, savanna management

\section{Introduction}

Invasive tree species have become a management priority for biologists in the Great Plains. Changes in fire regimes and land use have allowed woody communities to become dominant on the landscape (Ortmann et al. 1996). Changes in habitat composition and structure should result in shifts in the local breeding bird communities. We explored this hypothesis by focusing on savanna and forested Songbird habitats (Figure 1) in the valley of the Niobrara River in northern Nebraska.

Fires frequently occurred in the Niobrara Valley and played an important role in grassland prairie and oak savanna development prior to European settlement. Fire helped to maintain biodiversity in transitional habitats by creating heterogeneous patches. Fires converted areas back to grassland while leaving isolated woodland patches in the grassland matrix (Steuter et al. 1990). Recently, Griebel et al. (1998) found that bird species richness was higher on burned as opposed to unburned areas in this region. Lightning strikes caused many fires, although some can be attributed to Native American cultural practices (Ansley \& Rasmussen 2005; Taylor 2005). Fire suppression in the last century resulted in the decline of grassland and open savanna hab- itat, facilitating the intrusion of eastern red cedar (Juniperus virginiana) and other woody species (Steinauer \& Bragg 1987). Originally, cedar grew primarily along the steep valleys of the Niobrara River (Ortmann et al. 1996), but fire suppression, combined with hardiness, encouraged cedar to encroach into areas throughout The Nature Conservancy's Niobrara Valley Preserve (hereafter, Preserve). Eastern red cedar's expansion simplifies the flora of the Niobrara River Valley, because cedar outcompetes many other plant species (Gehring \& Bragg 1992). Cedar had increased in abundance in hardwood savannas, grasslands, hardwood forests, and ponderosa pine forests, all habitat types in which cedar was historically a small component (TNC Niobrara Valley Preserve 1999). The Preserve is currently working toward restoring the bottomland area to grassland prairie, oak savanna, and cottonwood-willow forest through a combination of cedar harvest and prescribed burns (TNC Niobrara Valley Preserve 1999). The goal of management is to restore the area back to a state that reflects a history of disturbance by fire. However, cedar removal could negatively affect wildlife populations that utilize this relatively new forest habitat.

Although eastern red cedar encroachment is an issue throughout the Midwest, little research has addressed the 


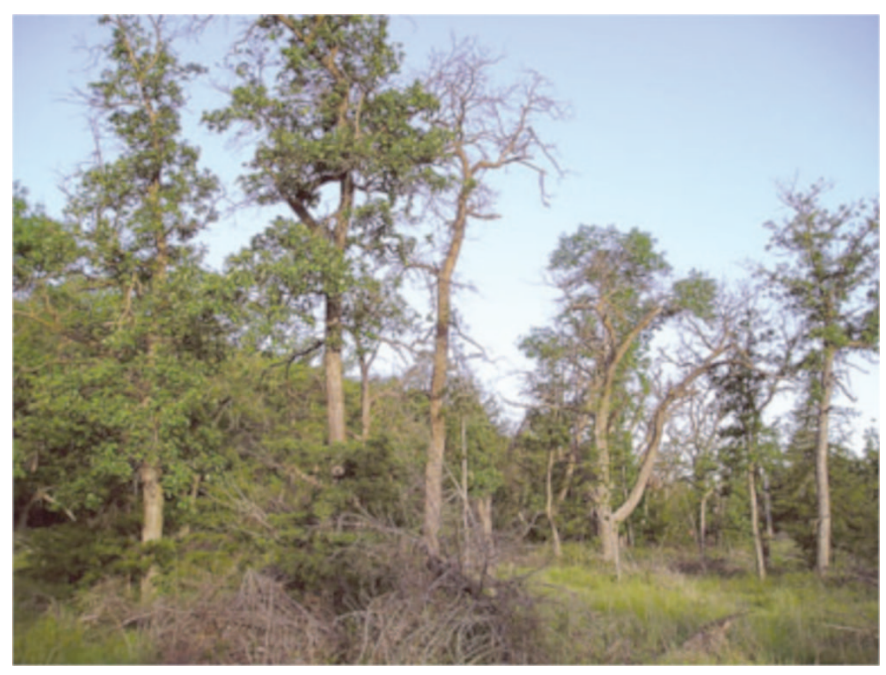

Figure 1. Hardwood savanna following physical removal of eastern red cedar at the Niobrara Valley Preserve in Nebraska, 2005. Note remaining cedars in midstory at left and right, as well as slash pile in foreground. Savannas transition into hardwood forests along the river corridor, as shown in background at left.

effects of red cedar removal on avian populations. Endemic grassland bird species have declined consistently due to habitat loss (PeterJohn et al. 1995). There are 330 bird species that breed on the Great Plains (Samson et al. 2004). Herkert et al. (2003) suggest that habitat fragmentation may be a cause for the decline in grassland species, because fragmentation increases the chances of nest predation. Birds are excellent bioindicators of habitat change because they can quickly move and colonize new areas (Furness et al. 1993). Bird counts may be an indicator of environmental conditions and habitat quality, and bird counts have been used and accepted as a basis for management decisions (Bock \& Jones 2004). The high diversity of Songbird species on the Preserve allowed us to monitor habitat associations and response to cedar removal.

Within this context, we hypothesized that habitats with lower densities of red cedar would have more diverse avian communities; cedar removal at our study site should provide habitat that would favor species that prefer open environments containing woody vegetation, such as the Eastern Kingbird (Tyrannus tyrannus), Brown Thrasher (Toxostoma rufum), American Goldfinch (Carduelis tristis), Field Sparrow (Spizella pusilla), Blue Grosbeak (Guiraca caerulea), Indigo Bunting (Passerina cyanea), and Lark Sparrow (Chondestes grammacus)-all species that are declining in central and eastern areas of the country (Davis et al. 2000; Sauer et al. 2008). Oak savannas, with their mixture of grassland and woody species, provide a good environment for these species. Fire also increases the amount of standing dead trees or snags. Snags are favored by woodpeckers, cavity-nesting birds, and other species that use trees for singing perches, such as the Indigo Bunting. We also expected that dense cedar stands would have fewer forest nesting birds than stands of hardwood forest with less cedar (Davis et al. 2000).
Our goal was to determine the response of the breeding bird community to vegetation management. Our objectives were to (1) estimate species richness at our survey points and assess effects of habitat characteristics on community structure, and (2) assess effects of habitat characteristics on abundance of our target species.

\section{Methods}

\section{Study Area}

We conducted our research at the Niobrara Valley Preserve in north central Nebraska $\left(42.786^{\circ} \mathrm{N}, 100.032^{\circ} \mathrm{W}\right)$. Three types of woodlands (eastern deciduous, northern boreal, and western coniferous) converge with mixed-grass prairie, tallgrass prairie, and sandhills prairie in the valley of the Niobrara National Scenic River. The diverse matrix of habitats supports a diverse avian community; Brogie and Mossman (1983) observed and recorded more than 200 bird species in this area. The Nature Conservancy manages 24,281 ha in the Niobrara River Valley, which is designated as the Niobrara Valley Preserve. The Niobrara Valley is ecologically significant because it is an area where eastern and western bird species hybridize (Labedz 1998). Most of the land surrounding the Niobrara River is privately owned.

We selected two sites on the south side of the Niobrara River on the eastern portion of the Preserve where previous cedar removal, 1-3 years prior to our study, had created a matrix of habitats (Figure 1). The habitat was fragmented with rapid transitions between patches of forest and grassland. Forest habitats were dominated by mature bur and pin oak (Quercus macrocarpa and Q. palustris) and eastern red cedar; pioneer age classes of cedars had reached mature sizes in the subcanopy, with new age classes encroaching in the understory and midstory. Grassland patches were dominated by a mixture of cool and warm season species encroached by small size classes of cedars and smooth sumac (Rhus glabra).

In both study areas, we designated a line transect that ran across habitat transitions. At 40,100-m intervals along the transects, we selected a random distance $(20-60 \mathrm{~m})$ and direction to place an avian survey point (Figure 2). We used metal tags to label 40 points and recorded their Universal Transverse Mercator (UTM) coordinates. Our goal was to have a representation of potential Songbird habitats characterized by grassland, forests with standing red cedar, forests with cleared red cedar, and hardwood forest (no cedar encroachment). Points were located on alternating sides of the line transect. Each survey point was marked with pink flags or ribbon. We recorded spatial coordinates at each point to aid in spatial analysis and facilitate year-to-year data collection.

\section{Avian Target Species}

We used data from all bird species for our community-level analyses, as rare or less common species may be especially sensitive to habitat changes. We focused our population-level efforts on five species: Ovenbird (Seiurus aurocapillus), Redeyed Vireo (Vireo olivaceus), Indigo Bunting, House Wren 


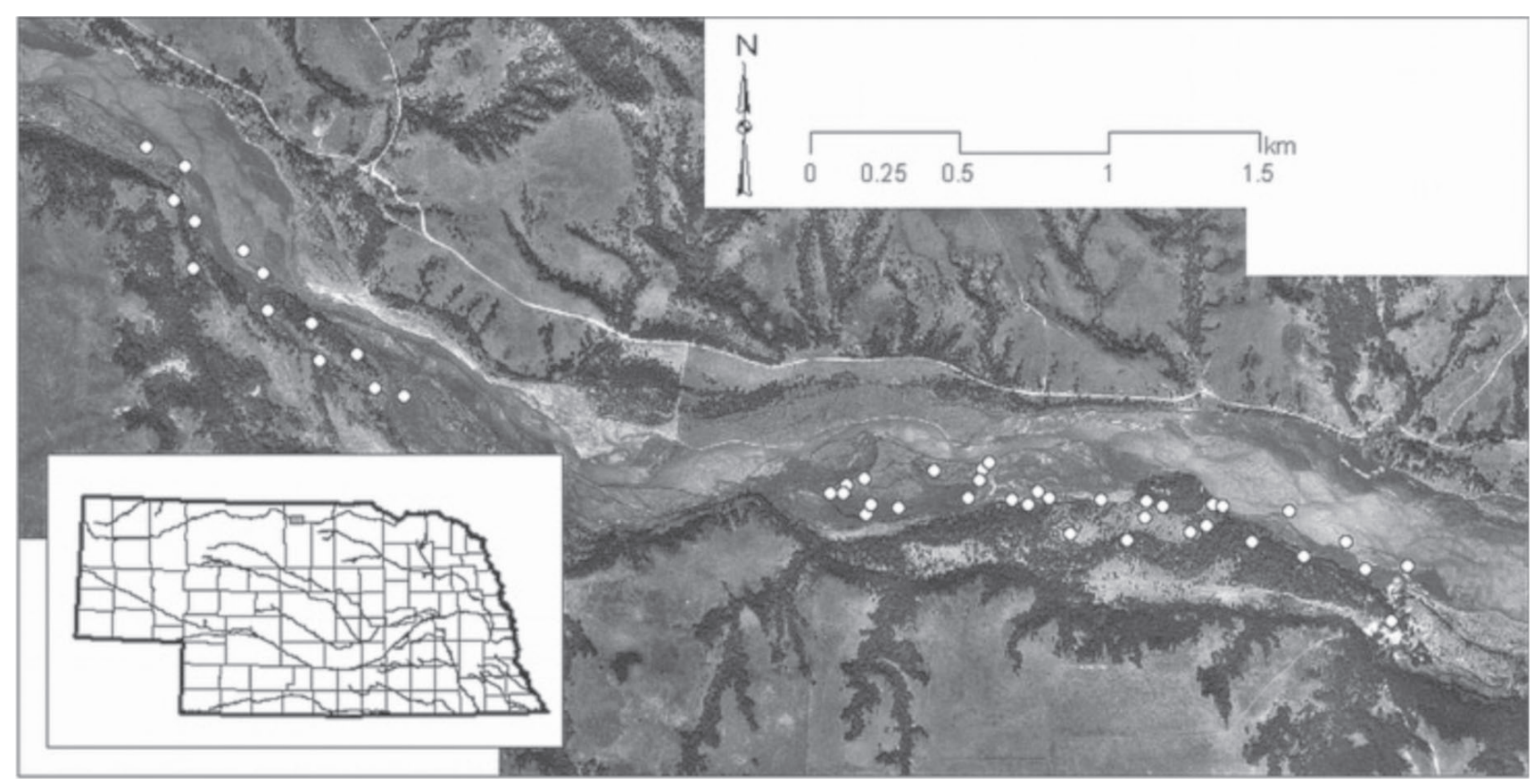

Figure 2. Location of point counts at two study sites at the Niobrara Valley Preserve in Nebraska during 2004 and 2005 . Shaded polygon in inset shows approximate location of Preserve along the Niobrara River.

(Troglodytes aedon), and Spotted Towhee (Pipilo maculates). We chose each of our target species because they were commonly reported during our early surveys, and they represent a variety of habitat preferences that are useful to evaluate effects of cedars on the avian community. The Ovenbird is a groundnesting bird found in woodlands. The Red-eyed Vireo is an open-cup mid-canopy nesting bird also found in woodlands. The Indigo Bunting is found in successional scrub habitats and nests low to the ground in an open-cup nest. Indigo Bunting populations are declining in Nebraska. The House Wren is a cavity nesting, mid-canopy nesting species found in successional scrub habitat. The Spotted Towhee is a short distance migrant that nests near the ground in successional scrub habitat. Indigo Buntings are declining in Nebraska (3.2\%/year), whereas Ovenbird populations are declining in the vicinity of our study area (1.5\%/year). Red-eyed Vireo, House Wren, and Spotted Towhee have stable populations in Nebraska (data range: 1966-2007; Sauer et al. 2008).

\section{Sampling Methods}

Bird Surveys. We used unlimited radius point count surveys (Johnson 1995) to estimate bird abundance and species richness. We conducted surveys twice each week during the breeding season in June and July, for a total of 16 surveys per point; all points were surveyed on the same day.

We conducted point count surveys (Buckland et al. 2001) between 0530 to 0930 hours, weather permitting. We recorded all birds seen or heard within the area. We waited 1 minute before starting the 5-minute survey at each survey point in order to allow birds in the area to settle in response to the disturbance. Observers were rotated between points, and we rotated the start direction to reduce potential biases (Buckland et al. 2001).
Vegetation Structure and Composition. We quantified vegetation structure and composition at each avian survey site. We estimated forest canopy cover and vertical and horizontal structure of vegetation less than $2 \mathrm{~m}$ in height. A concave densiometer (Lemmon 1956) was used to measure forest canopy cover. A horizontal density board $(2 \times 0.5$ m; Nudds 1977) was utilized to measure vegetation density less than $2 \mathrm{~m}$ in height in forested areas. We measured height and density of vegetation using a 1-m visual obstruction pole (Robel et al. 1970). The number of red cedar, hardwood trees, and snags was recorded within a $10-\mathrm{m}$ radius of the survey point. Densiometer readings and tree counts were recorded at the point, whereas the cover board was placed approximately $10 \mathrm{~m}$ away from the point in a randomly chosen direction.

\section{Statistical Analysis}

Community-Level Analyses. We used PRIMER (version 6; Primer-E Ltd. 2001) to determine which vegetation variables would best describe similarity in bird communities among point counts. Our community composition data consisted of the number of each species observed at each point. We normalized the bird survey data using a fourth root transformation (Clarke \& Gorley 2001) and we calculated a Bray-Curtis similarity index for all pairs of survey points (Krebs 1999). We used eight vegetation variables (canopy openness, horizontal vegetation density: visual obstruction pole, cedar density, hardwood tree density, horizontal vegetation density: 0-0.5 m, 0.5-1 m, 1-2 m [board], and snags) to assess trends in similarity of the bird communities at each point. These variables were normalized using a log transformation (Clarke \& Gorley 2001). Using the stress coefficients as a guide (Clarke \& Gorley 2001), we es- 


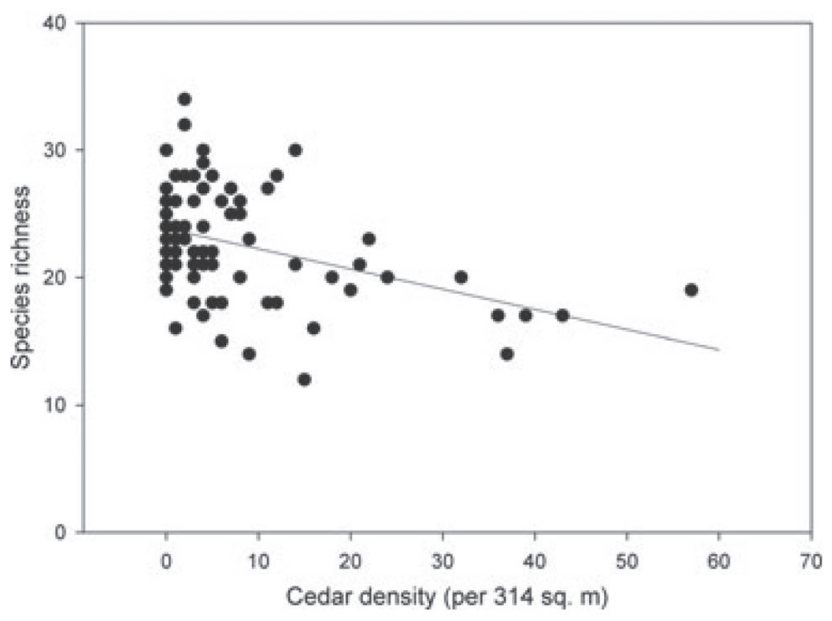

Figure 3. Relationship between species richness and cedar density at $10-\mathrm{m}$ radius $\left(314 \mathrm{~m}^{2}\right)$ sampling locations in the Niobrara Valley Preserve during 2004-2005.

tablished a two-dimensional, nonmetric scaling plot to display the similarity among survey sites.

Population-Level Analyses. We used the program PRESENCE (MacKenzie et al. 2002; Hines 2006) to assess the effect of habitat characteristics on Songbird species' relative abundance at our survey points. PRESENCE analyses account for incomplete detection of birds during repeated surveys. We used a binomial mixture model approach developed by Royle (2004) to estimate abundance adjusted for detectability from our survey data. We used a separate analysis for our five target species; for each species, we estimated $\lambda_{\mathrm{i}}$ (abundance in site $i$ ), $\lambda$ (mean abundance), and $p_{\text {it }}$ (probability that an individual bird would be detected in site $i$ during survey $t$, given it is present).

We performed an initial assessment, for each species, to determine whether detectability $(p)$ varied by habitat characteristics at each point. We compared four models: $\lambda() p.($.$) ,$ constant detectability across survey points; $\lambda() p.($ cedar), detectability varies with density of cedar; $\lambda($.$) p(canopy), de-$ tectability varies with canopy opening (measured with densitometer); and $\lambda() p.($ hardwood), detectability varies with density of hardwood across survey points. We used Akaike's Information Criterion (AIC) scores (Burnham \& Anderson 2002) to select the model that best described detectability for each species. Then, we modified the best detectability model to assess effects of habitat on bird abundance $(\lambda)$. For each species, we created an a priori, limited set of singlefactor models to describe potential effects of habitat on abundance within our study site. These models served as hypotheses, and we arrived at the group of potential effects from literature sources and our observations. We used a separate model selection process for each species. We selected model effects, for each species, from the following vegetative components: canopy cover, total snags within $10 \mathrm{~m}$, height and density of vegetation, understory vegetation density at low $(0-30 \mathrm{~cm})$, mid $(30-100 \mathrm{~cm})$, and high $(100-200 \mathrm{~cm})$ levels, cedar density, and hardwood density.

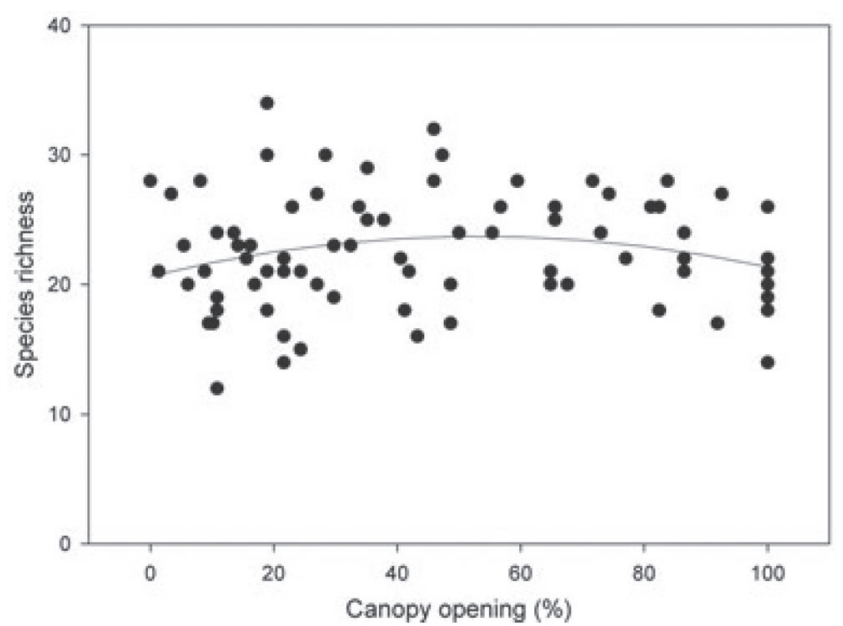

Figure 4. Relationship of species richness and canopy opening (\%) at sampling locations at the Niobrara Valley Preserve during 20042005. Hypothesized relationship represents intermediate disturbance hypothesis.

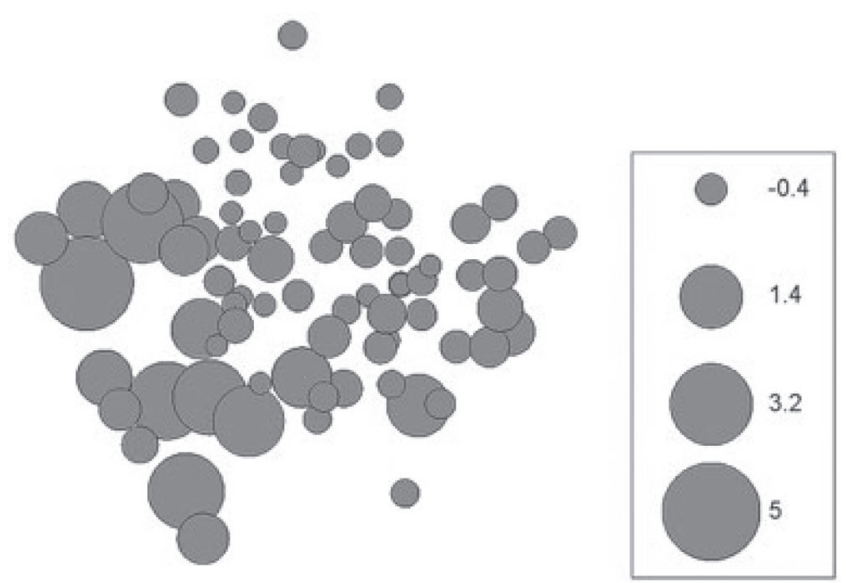

Figure 5. Nonmetric multi-dimensional (in two dimensions) scaling plot of similarity indices for each bird survey point at the Niobrara Valley Preserve during 2004-2005. Points are arranged so that sites with more similar bird communities are closer in space. Size of bubble representing point shows standardized density of cedar at the survey point.

\section{Results}

\section{Bird Surveys}

Community Analyses. We recorded 63 species in 2004 (4372 obs) and 61 species in 2005 (2871 obs). The top vegetation structure and composition models for explaining variability in community similarity among survey points were cedar abundance $\left(r^{2}=0.248\right)$ and canopy cover + cedar abundance $\left(r^{2}=0.181\right)$. In fact, cedar was present in all top models. Survey points with high cedar density had low species richness (Figure 3; $\beta=-0.158, \mathrm{SE}=0.041 ; p<0.01$ ). Species richness appeared to be fairly independent of canopy cover, although mid-level of canopy cover tended to have more species 


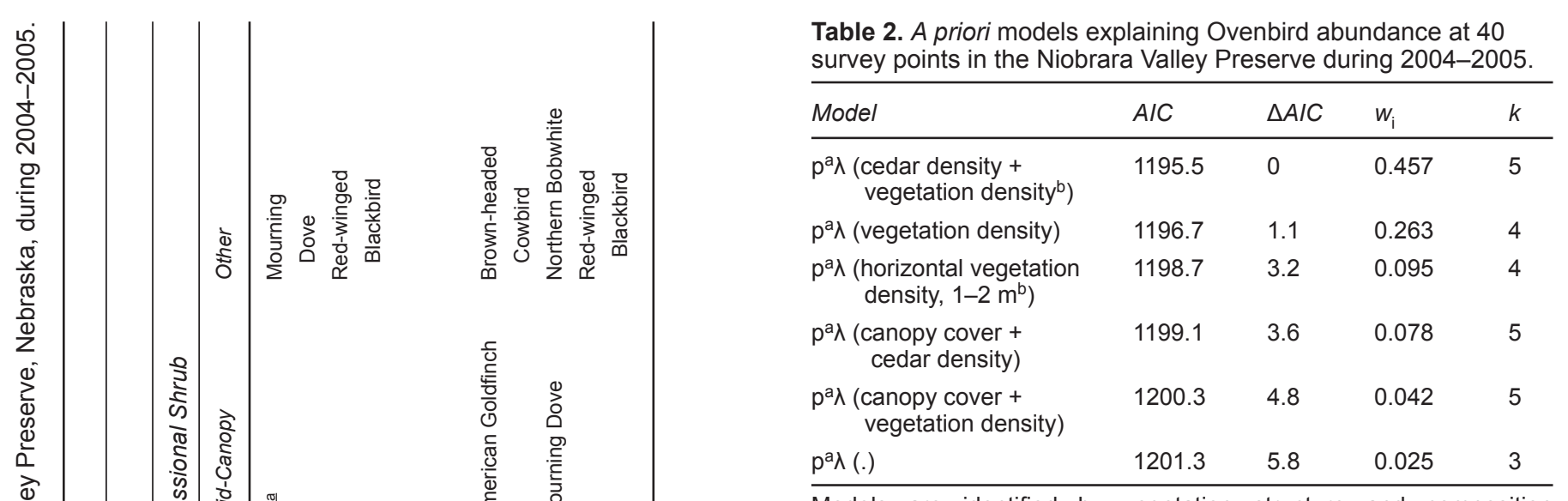

Models are identified by vegetation structure and composition variables, and $k$ represents the number of parameters in each model. Models with lower $\triangle \mathrm{AIC}$ values and larger Akaike weights $\left(w_{\mathrm{i}}\right)$ have more support. Models shown contributed to approximately $90 \%$ of the total model weight. Models contributing to less than $90 \%$ cumulative model weight (in order) included models with abundance effects of: horizontal vegetation density, $0-0.5 \mathrm{~m}$; number of snags; horizontal vegetation density, 0.5-1.0 m; canopy cover; cedar density + hardwood density; cedar density; horizontal vegetation density, 1-2 $\mathrm{m}+$ + 0-0.5 m; cedar density + hardwood density + canopy cover; hardwood density; canopy cover + horizontal vegetation density, 0 $0.5 \mathrm{~m}+0.5-1.0 \mathrm{~m}$.

a. Detection rate varied by canopy cover in all models.

b. Vegetation density represents VOR measured with Robel pole, horizontal vegetation density determined by $0.5 \times 2-\mathrm{m}$ coverboard.

(Figure $4 ; p=0.22$ ). Cedar density was the single variable that best explained community similarity between points (Figure 5). High-density cedar sites had more ground-nesting successional shrub habitat species, whereas the low density sites, overall, had more species diversity with an increase in cavity-nesting and woodland species (Table 1). Species in low density cedar sites represented all guilds.

Population-Level Analyses. Abundance of three of our five target Songbird species varied with respect to habitat structure and composition. Ovenbird abundance was highest at survey points with more abundant cedar trees, but with lower visual obstruction readings $\left(\right.$ Table $2 ; \beta_{\text {cedar }}=0.143, \mathrm{SE}=$ $0.084 ; \beta_{\mathrm{VOR}}=-0.191, \mathrm{SE}=0.083$ ). Abundance of House Wrens increased as the number of snags increased and as vegetation density at $0-0.5 \mathrm{~m}(\mathrm{CBlow})$ increased $\left(\beta_{\mathrm{CBlow}}=0.113, \mathrm{SE}\right.$ $=0.056 ; \beta_{\text {snags }}=0.131, \mathrm{SE}=0.058 ;$ Table 3$)$. The cedar density model was not highly ranked $(\triangle \mathrm{AIC}=14.0$, model weight $<0.001$ ), but House Wren abundance was negatively affected by cedar density $\left(\beta_{\text {cedar }}=-0.385, \mathrm{SE}=0.074\right)$. Spotted Towhees decreased as vegetation density at 1-2 m (CBhigh) increased $\left(\beta_{\mathrm{CBhigh}}=-0.137, \mathrm{SE}=0.067\right)$, but the effect was marginal (null model: $\triangle \mathrm{AIC}=1.8$; Table 4). Spotted Towhees were not affected by cedar density $\left(\beta_{\text {cedar }}=-0.025, \mathrm{SE}\right.$ $=0.069$ ). Indigo Bunting abundance did not vary with any of the vegetation covariates (null model selected, AIC weight $=0.287)$ including cedar density $\left(\beta_{\text {cedar }}=-0.072, \mathrm{SE}=0.108\right)$. Similarly, Red-eyed Vireo abundance did not show strong signs of varying with habitat characteristics (null model selected, AIC weight $=0.375$ ); Red-eyed Vireos increased with cedar density $\left(\beta_{\text {cedar }}=0.168, \mathrm{SE}=0.071\right)$, although the cedar 
Table 3. A priori models explaining House Wren abundance at 40 survey points in the Niobrara Valley Preserve during 2004-2005.

\begin{tabular}{lllll}
\hline Model & $A / C$ & $\triangle A I C$ & $w_{\mathrm{i}}$ & $k$ \\
\hline $\begin{array}{l}\mathrm{p}^{\mathrm{a}} \lambda \text { (horizontal } \\
\text { vegetation density, } \\
\quad 0-0.5 \mathrm{~m}+\text { snags) }\end{array}$ & 1795.1 & 0.0 & 0.828 & 4 \\
$\mathrm{p}^{\mathrm{a} \lambda(.)}$ & 1798.2 & 3.2 & 0.171 & 2 \\
\hline
\end{tabular}

Models are identified by vegetation structure and composition variables used in models, and $k$ represents the number parameters for each model. Models with lower $\triangle \mathrm{AIC}$ values and larger Akaike weights $\left(w_{i}\right)$ have more support. Models shown contributed to $90 \%$ of the total model weight. Models contributing to less than $90 \%$ cumulative model weight (in order) included models with abundance effects of: cedar density; horizontal vegetation density, $0-0.5 m+0.5-1.0 m$ $+1-2 \mathrm{~m}$; horizontal vegetation density, $1-2 \mathrm{~m}+$ number of snags + canopy cover; canopy cover; horizontal vegetation density, 1-2 m; horizontal vegetation density, $1-2 \mathrm{~m}+$ number of snags; hardwood density; vegetation density ${ }^{b}$; horizontal vegetation density, 0.5-1 m; number of snags; horizontal vegetation density, $0-0.5 \mathrm{~m}$; horizontal vegetation density, $1-2 m+$ canopy cover.

a. Detection rate did not vary by any habitat characteristic; $p($.$) in all$ models.

b. Horizontal vegetation density determined by $0.5 \times 2-\mathrm{m}$ coverboard.

Table 4. A priori models explaining Spotted Towhee abundance at 40 survey points in the Niobrara Valley Preserve during 20042005.

\begin{tabular}{|c|c|c|c|c|}
\hline Model & $A I C$ & $\triangle A I C$ & $w_{\mathrm{i}}$ & $k$ \\
\hline $\begin{array}{l}\mathrm{p}^{\mathrm{a}} \lambda \text { (horizontal vegetation } \\
\text { density, } 1-2 \mathrm{~m}^{\mathrm{b}} \text { ) }\end{array}$ & 1526.4 & 0 & 0.407 & 4 \\
\hline $\mathrm{p}^{\mathrm{a}} \lambda\left(\right.$ vegetation density $\left.{ }^{\mathrm{b}}\right)$ & 1528.0 & 1.6 & 0.186 & 4 \\
\hline$p^{a} \lambda()$. & 1528.2 & 1.8 & 0.164 & 3 \\
\hline $\begin{array}{l}\mathrm{p}^{\mathrm{a}} \lambda \text { (horizontal vegetation } \\
\text { density, } 0-0.5 \mathrm{~m} \text { ) }\end{array}$ & 1529.1 & 2.8 & 0.103 & 4 \\
\hline $\mathrm{p}^{\mathrm{a} \lambda}$ (hardwood density) & 1529.8 & 3.4 & 0.073 & 4 \\
\hline
\end{tabular}

Models are identified by vegetation structure and composition variables used in models, and $k$ represents the number parameters for each model. Models with lower $\triangle \mathrm{AIC}$ values and larger Akaike weights $\left(w_{\mathrm{i}}\right)$ have more support. Models shown contributed to $90 \%$ of the total model weight. Models contributing to less than $90 \%$ cumulative model weight (in order) included models with abundance effects of: horizontal vegetation density, 0.5-1 m; cedar density; hardwood density + horizontal vegetation density, $0.5-1 \mathrm{~m}$; number of snags; cedar density + vegetation density; cedar density + horizontal vegetation density, 1-2 m; cedar density + horizontal vegetation density, $0.5-1 \mathrm{~m}$; cedar density + horizontal vegetation density, $0-0.5$ $\mathrm{m}$; canopy cover.

a. Detection rate varied by canopy cover in all models.

b. Vegetation density represents VOR measured with Robel pole, horizontal vegetation density determined by $0.5 \times 2-\mathrm{m}$ coverboard.

density model was not highly ranked $(\triangle \mathrm{AIC}=22.6$, model weight $<0.001$ ).

Detection rates of four species were influenced by habitat during surveys. Detection rates used for abundance analyses in program PRESENCE showed a similar trend. Ovenbird $\left(\beta_{\text {canopy }}=-0.2108, \mathrm{SE}=0.11\right)$ and Red-eyed Vireo $\left(\beta_{\text {canopy }}=\right.$ $-0.478, \mathrm{SE}=0.107)$ detection rates dropped as canopy opening increased. Indigo Bunting detection rates increased with cedar density $\left(\beta_{\text {cedar }}=1.174, \mathrm{SE}=0.072\right)$. Detection of House Wren did not vary with any habitat measures (null model selected). Detection of Spotted Towhee increased marginally with canopy opening $\left(\beta_{\text {canopy }}=0.126, \mathrm{SE}=0.076\right.$; null model $\triangle$ AIC : 0.95 ). We used the canopy opening model as the structure for detection of Spotted Towhees in our subse- quent analyses to account for potential effects of detection on our abundance estimates.

\section{Discussion}

Vegetation structure affected bird population and community structure in the Niobrara River Valley. In particular, we found that variation of cedar density affected avian diversity. Cedar density was the best predictor of avian community similarity; sites more similar in cedar density tended to have more similar communities. Bird species richness was highest in areas with low density of cedar. Thus, our study implies that cedar infestations will decrease species richness in systems similar to the Niobrara River corridor. Similarly, Skowno and Bond (2003) found that changes in vegetation structure caused by bush encroachment in mesic South African savannas resulted in changes to the composition of avian communities. On our study site, all avian guilds were present at study sites with low cedar density; as cedar density increased total species richness and guild representation were depressed. Our results suggest that cedar invasions cause shifts in bird community composition over relatively small spatial scales in the Preserve. Davis et al. (2000) reported a general decline of canopy foraging species and an increase in ground-foraging species after fire-based restorations of savannas in central Minnesota. Our study is one of the first to directly document effects of cedar density on avian species in a management context. Cedar management is a common goal for Midwestern agencies and conservation organizations, and it appears much of the management is based on anticipated or perceived effects; we encourage similar research at other sites to help guide management decisions. Our inferences are limited to the structure of the avian community at the Preserve during the breeding season; the effects of cedar removal on avian productivity, as well as the composition of the community of migratory or winter residents (Kricher 1975; Thompson \& Fritzell 1988) should also be evaluated.

Mixed habitats tended to have higher species richness, due to moderate canopy cover and a diversity of habitat structure as predicted by the intermediate disturbance hypothesis (Connell 1978). Fink et al. (2006) found that densities of shrubland birds, found in timber-managed areas of regenerating forests, were often greater than those in traditional shrub habitats. Frost (2007) found that species richness, as measured by mist net capture data, tended to be higher in areas of mixed habitat. Mixed habitats (shrub-type habitat) supported a diverse community of shrub and forest-dwelling birds, and community composition changed rapidly with habitat structure. Welsh and Lougheed (1996) found similar fine-scale changes in community composition in response to forest habitat.

Three of our target species responded to cedar density. Ovenbirds are normally considered a forest interior species; yet, we found no effect of canopy opening on Ovenbirds. Instead, they responded positively to higher cedar density and low vegetation density on the ground. In the matrix of deciduous forest, Ovenbirds may respond to the protection of cedars, which create thick habitat. Regardless, the high density of Ovenbirds in this fragmented forest habitat on the edge of 
their range is a unique finding. Biologists may find this population of Ovenbirds to be highly relevant to regional studies of population stability.

Red-eyed Vireos also responded positively to cedar density; in contrast, local populations of House Wrens declined as cedar densities increased. Our results suggest that cedar infestations may have effects on local populations that are not expected by managers. At the Preserve, the local population of two neotropical migrants appeared to be influenced positively by thicker forests created by cedar infestation. Management decisions are usually complex, and we encourage managers to (1) set specific objectives for restoration work, and (2) use monitoring schemes to evaluate the effects of management in a structured framework (Gregory \& Keeney 2002).

\section{Conclusions}

Diverse bird communities along the Niobrara River corridor will be maintained with management that ensures a matrix of diverse habitats. Our data confirm that habitat composition and structure drive much of the variation observed in bird community composition and population density at local scales within the Preserve. Songbird species richness is highest in open and mixed habitats; thus, the Preserve's goal of restoring oak savanna habitat to portions of the river corridor should be a positive step to maintain high diversity. Silviculture is critical to effective management of early successional communities (Thompson \& DeGraaf 2001). We encourage managers to use fine-scale silviculture, fire, and grazing to provide a diverse mix of open grassland, shrubdominated grasslands, and woodland patches. Fire and grazing produce a natural scale of habitat heterogeneity which is manifested in the Niobrara Valley as patches of woodlands within a grassland matrix (Steuter et al. 1990). Heterogeneity provides a variety of niches that can be utilized by generalist and specialist species (Danielson 1991); habitat edges within the matrix provide higher species richness, because both shrub land and forest birds use it for breeding (Strelke \& Dickson 1980).

Managers struggle with complex decisions regarding the management of woody vegetation in early successional communities throughout the world. Generally, removal or thinning of encroaching woody species is thought to be a prudent management action to restore plant and animal communities. For example, avian nest survival increased following thinning of mesquite (Prosopis glandulosa) in grasslands of New Mexico's Chihuahuan Desert (Mason et al. 2005) and managers of Acacia-dominated thornveld habitats in southern Africa must address woody encroachment to reduce impacts on regional biodiversity (Skowno \& Bond 2003; Neke \& Du Plessis 2004). On our study site, future fine-scale management aimed to clear cedar from local areas, may increase species diversity throughout the Preserve for Songbirds by contributing to the creation of a mosaic of local habitats. However, we predict that cedar removal, at any scale, will affect the composition of bird communities. It is critical that managers identify objectives for management, including desired avian community composition, to make effective habitat management decisions.

\section{Implications for Practice}

- Fire has been an essential component of the Niobrara River Valley's ecosystem, and eastern red cedar has increased in abundance with the reduction in fire frequency.

- Cedar infestation affects the composition of the avian community; increased cedar encroachment is likely to decrease avian species richness.

- Fine-scale removal of cedars should increase diversity of the bird community.

- Woody species removal may negatively affect some avian species in any ecosystem; thus, monitoring (before and after restoration) is a critical component to determine the success of a restoration program.

Acknowledgments - Funding for this project was provided by the National Park Service (Great Plains Cooperative Ecosystem Studies Unit) and the Nebraska Game and Parks Commission (State Wildlife Grant program). The Nature Conservancy's Niobrara Valley Preserve provided research housing, logistical support, and access to the study site. C. Thompson, Niobrara National Scenic River, assisted with project development. We are grateful to our research technicians. The School of Natural Resources, University of Nebraska-Lincoln, provided office and computer facilities. This article was improved through comments of P. Cale, P. Porneluzi, and an anonymous reviewer. This research was supported by Hatch Act funds through the University of Nebraska Agricultural Research Division, Lincoln, Nebraska.

\section{Literature Cited}

Ansley, R. J., and G. A. Rasmussen. 2005. Managing native invasive juniper species using fire. Weed Technology 19:517-522.

Bock, C. E., and Z. F. Jones. 2004. Avian habitat evaluation: Should counting birds count? Frontiers in Ecology and the Environment 2:403-410.

Brogie, M. A., and M. J. Mossman. 1983. Spring and summer birds of the Niobrara Valley Preserve area, Nebraska: An annotated checklist. Nebraska Bird Review 51:44-51.

Buckland, S. T., D. R. Anderson, K. P. Burnham, J. L. Laake, D. L. Borchers, and L. Thomas. 2001. Introduction to distance sampling: Estimating abundance of biological populations. Oxford University Press, Cornwall.

Burnham, K. P., and D. R. Anderson. 2002. Model selection and multimodel inference: A practical information-theoretic approach. Springer-Verlag, New York, New York.

Clarke K. R., and R. N. Gorley. 2001. Primer v5: User manual and tutorial. PRIMER-E Ltd., Plymouth, U.K.

Connell, J. H. 1978. Diversity in tropical rain forests and coral reefs. Science 199:1302-1310.

Danielson, B. J. 1991. Communities in a landscape: The influence of habitat heterogeneity on the interactions between species. American Naturalist 138:1105.

Davis, M. A., D. W. Peterson, P. B. Reich, M. Crozier, T. Query, E. Mitchell, J. Huntington, and P. Bazakas. 2000. Restoring savanna using fire: Impact on the breeding bird community. Restoration Ecology 8:30-40. 
Fink, A. D., F. R. Thompson III, and A. A. Tudor. 2006. Songbird use of regenerating forest, glade, and edge habitat types. Journal of Wildlife Management 70:180-188.

Furness, R. W., J. J. D. Greenwood, and P. J. Jarvis. 1993. Can birds be used to monitor the environmental? Pages 1-41 in R. W. Furness, and J. J. D. Greenwood, editors. Birds as monitors of environmental change. Chapman and Hall, London.

Gehring, J. L., and T. B. Bragg. 1992. Changes in prairie vegetation under eastern red cedar (Juniperus virginiana L.) in an eastern Nebraska bluestem prairie. American Midland Naturalist 128:209-217.

Gregory, R. S., and R. L. Keeney. 2002. Making smarter environmental management decisions. Journal of the American Water Resources Association 38:1601-1612.

Griebel, R. L., S. L. Winter, and A. A. Steuter. 1998. Grassland birds and habitat structure in sandhills prairie managed using cattle or bison plus fire. Great Plains Research 8:255-268.

Herkert, J. R., D. L. Reinking, D. A. Wiedenfeld, M. Winter, J.L. Zimmerman, W. E. Jensen, et al. 2003. Effects of prairie fragmentation on the nest success of breeding birds in the midcontinental United States. Conservation Biology 17:587-594.

Hines, J. E. 2006. PRESENCE2-Software to estimate patch occupancy and related parameters. USGS-PWRC; online http:// www.mbrpwrc.usgs.gov/software/presence.html

Johnson, D. H. 1995. Point counts of birds: what are we estimating? Pages 117-123 in C. J. Ralph, J. R. Sauer, and S. Droege, editors, Monitoring bird populations by point counts. Pacific Southwest Research Station Forest Service, Albany, California.

Krebs, C. J. 1999. Ecological Methodology. 2nd edition. AddisonWelsey Educational Publishers, Inc., Menlo Park, California.

Kricher, J. C. 1975. Diversity in two wintering bird communities: possible weather effects. Auk 92:766-777.

Labedz, T. E. 1998. Pages 173-192 in A. S. Bleed, and C. A. Flowerday, editors. An atlas of the Sandhills. Conservation and Survey Division, Institute of Agriculture and Natural Resources, University of Nebraska, Lincoln.

Lemmon, P. E. 1956. A spherical densiometer for estimating forest overstory density. Forestry Science 2:314-320.

MacKenzie, D. I., J. D. Nichols, G. B. Lachman, S. Droege, J. A. Royle, and C. A. Langtimm. 2002. Estimating site occupancy rates when detection probabilities are less than one. Ecology 83:2248-2255.

Mason, L. C., M. J. Desmond, and M. S. Agudelo. 2005. Influence of grassland type, nest type, and shrub encroachment on predation of artificial nests in Chihuahuan Desert grasslands. Western North American Naturalist 65:196-201.

Neke, K. S., and M. A. Du Plessis. 2004. The threat of transformation: Quantifying the vulnerability of grasslands in South Africa. Conservation Biology 18:466-477.

Nudds, T. D. 1977. Quantifying the vegetation structure of wildlife cover. Wildlife Society Bulletin 5:113-117.
Ortmann, J., J. Stubbendieck, G. H. Pfeiffer, R. A. Masters, W. H. Schacht. 1996. Management of Eastern Redcedar on grasslands (NebGuide G1308). University of Nebraska-Lincoln Extension, Lincoln.

PeterJohn, B. G., J. R. Sauer, and C. S. Robbins. 1995. Population trends from the North American breeding bird survey. Pages 3-39 in T. E. Martin, and D. M. Finch, editors. Ecology and management of neotropical migratory birds. Oxford University Press, New York.

Primer-E Ltd. 2001. Primer for Windows, Version 6. Plymouth, U.K.

Robel, R. J., J. N. Briggs, A. D. Dayton, and L. C. Hulbert. 1970. Relationship between visual obstruction measurements and weight of grassland vegetation. Journal of Range Management 23:295-298.

Royle, J. A. 2004. N-mixture models for estimating population size from spatially replicated counts. Biometrics 60:108-115.

Samson, F. B., F. L. Knopf, and W. R. Ostlie. 2004. "Grasslands". USGS; online http://biology.usgs.gov/s\%2Bt/SNT/noframe/gr139.htm

Sauer, J. R., J. E. Hines, and J. Fallon. 2008. The North American Breeding Bird Survey, Results and Analysis 1966-2007. Version 5.15.2008. USGS Patuxent Wildlife Research Center, Laurel, Maryland.

Skowno, A. L., and W. J. Bond. 2003. Bird community composition in an actively managed savanna reserve, importance of vegetation structure and vegetation composition. Biodiversity and Conservation 12: 2279-2294.

Steinauer, E. M., and T. B. Bragg. 1987. Ponderosa Pine (Pinus ponderosa) invasion of Nebraska sandhills prairie. American Midland Naturalist 118:358-365.

Steuter, A. A., B. Jasch, J. Ihnen, and L. L. Tieszen. 1990. Woodland/grassland boundary changes in the Middle Niobrara Valley of Nebraska identified by $\delta^{13} \mathrm{C}$ values of soil organic matter. American Midland Naturalist 124:301-308.

Strelke, W. K., and J. G. Dickson. 1980. Effect of forest clear-cut edge on breeding birds in east Texas. Journal of Wildife Management 44:559-567.

Taylor, C. A. Jr. 2005. Prescribed burning cooperatives: Empowering and equipping ranchers to manage rangelands. Rangelands 27: 18-23.

Thompson, F. R. III, and R. M. DeGraaf. 2001. Conservation approaches for woody, early successional communities in the eastern United States. Wildlife Society Bulletin 29:483-494.

Thompson, F. R. III, and E. K. Fritzell. 1988. Ruffed grouse winter roost site preference and influence on energy demands. Journal of Wildlife Management 52:454-460.

TNC Niobrara Valley Preserve. 1999. Niobrara Valley Preserve Site Conservation Plan. The Nature Conservancy, Nebraska. 